\title{
Synthesis and Structure of a Cadmium Selenite-Sulfate $\mathrm{Cd}_{4}\left(\mathrm{SeO}_{3}\right)_{2}\left(\mathrm{SO}_{4}\right)_{2}$
}

\author{
Yiming Xic ${ }^{*}$ and Jihuai Wu \\ College of Materials Science and Engineering, Hagiao University. Quanzhou, Fuian 362021, P.R. China \\ ${ }^{*}$ E-mail: xym8790'àvahoo.com. on \\ Received April 27, 2007
}

Key Words : Cadınium. Crystal structure, Selenite. Sulfate

Metal selenites have been of research interest to scientists in chemistry and materials ${ }^{1}$ because of their novel structures and unusual optical, electrical and magnetic properties. which enable metal selenites to be applied as anisotropic semiconductive coatings, photovoltage sources, or photoelectric devices. ${ }^{2}$ lo date, many metal selenites have been synthesized." Among them. however, no group-12 selenitesulfate has been reported. Our interest in the selenite-based structures was concerned with the possible role of the stereochemically active lone pair of electrons as an invisible structure-directing agent to prepare unusual structures. The stereochemically active lone pair of electrons in $\mathrm{Se}^{\left[V^{\prime}\right.}$ generally leads to a pyramidal coordination for the selenite species. From synthetic and crystal chemistry viewpoint, it is suggested that this could cause the selenites to result in a noncentrosymmetric structure with interesting physical properties such as nonlinear optical second harmonic generation (SHG). ${ }^{+}$ Herein we describe the synthesis, structure and property of cadmium selenite-sulfate, $\mathrm{Cd}_{1}\left(\mathrm{SeO}_{3}\right)_{2}\left(\mathrm{SO}_{1}\right)_{2}(\mathbf{1})$, which is the first group- 12 selenite-sulfates and possesses a novel 3-D structure.

As for the reaction mechanism of preparing the title compound, we proposed a logical process as follows: firstly. the sulfur and selenium were oxidized as $\mathrm{SO}_{4}{ }^{2-}$ and $\mathrm{SeO}_{3}{ }^{2-}$ groups, respectively, then the $\mathrm{SO}_{4}{ }^{2-}$ and $\mathrm{SeO}_{3}{ }^{2-}$ groups bound to the cadmium center to form the result compound. Thus, the following equations may be given: $\mathrm{CdBr}_{2}-4 \mathrm{H}_{2} \mathrm{O}+\mathrm{S}-\mathrm{Se}$ $\rightarrow \mathrm{CdBr}_{2} \cdot 4 \mathrm{H}_{2} \mathrm{O}+\mathrm{SO}_{1}{ }^{2-}+\mathrm{SeO}_{3}{ }^{2-} \rightarrow \mathrm{Cd}_{4}\left(\mathrm{SeO}_{3}\right)_{2}\left(\mathrm{SO}_{4}\right)_{2}(1)$.

$\mathrm{X}$-ray diffraction analysis reveals that compound 1 features a 3-D structure with the cadmium atoms in three different coordination environments. An ORTEP drawing of

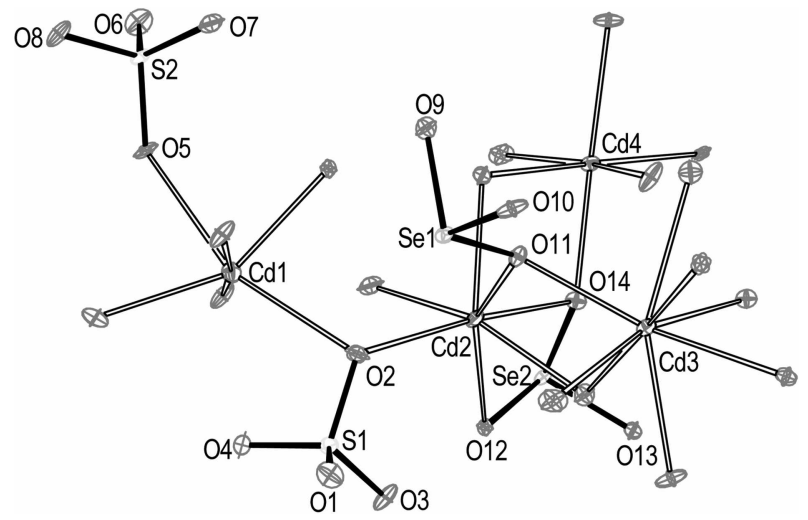

Figure 1. ORTF.P drawing of 1 with $40 \%$ themal ellipsoids. the asymmetric unit of $\mathbf{1}$ is shown in Figure 1. The four crystallographically independent cadmium atoms are grouped into three kinds of coordination geometries. The $\mathrm{CdI}$ and $\mathrm{Cd} 4$ atoms have a distorted octahedral geometry, coordinated to six oxygen atoms from the $\mathrm{SeO}_{3}{ }^{2-}$ and $\mathrm{SO}_{1}{ }^{2-}$ groups. Different from $\mathrm{CdI}$ and $\mathrm{Cd} 4$ atoms that are six-coordinated. the $\mathrm{C} d 2$ atom is coordinated by seven oxygen atoms to form mono-capped octahedron, and the bond lengths of $\mathrm{Cd}-\mathrm{O}$ are range from 2.236(4) to 2.572 (4) $\AA$ with an average value of $2.384(5) \AA$. The Cd3 atoms, which are the third kind of coordination geometries of cadmium atoms in 1 , are in a distorted square anti-prism environment, coordinated by eight oxygen atoms from the $\mathrm{SeO}_{3}{ }^{2-}$ and $\mathrm{SO}_{4}{ }^{2-}$ groups. yielding a decahedron. In $\mathbf{1}$, all the bond lengths of $\mathrm{Cd}-\mathrm{O}$ are in the normal range and comparable with those reported. ${ }^{3.5}$ All the $\mathrm{Se}^{1 Y}$ atoms are three-coordinated by three oxygen atoms in a distorted $\psi-\mathrm{SeO}_{3}$ tetrahedral geometry with the fourth site occupied by the lone-pair electrons (Figure 2),

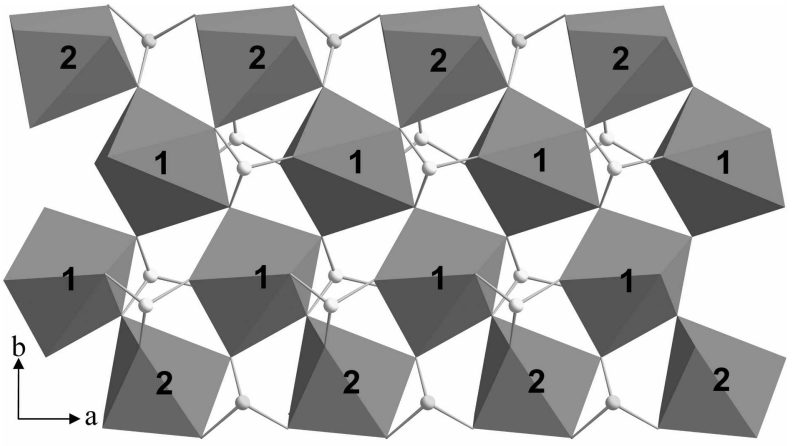

(a)

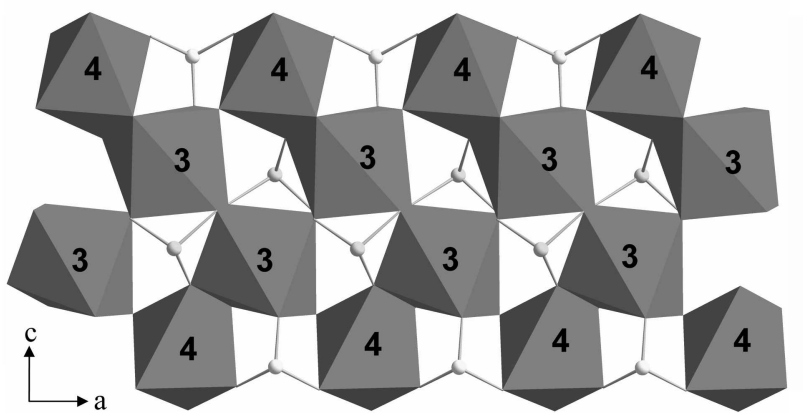

(b)

rigure 2. Polyhedral view of I shows two kinds of cyuadruplechain structures: (a) polyhedra comer-share to each other: (b) polyhedra corner-share and edge-share to each other. Yellow: S, green: Se. Numbers are the crystallographically distinct cadmium atoms. 
which are similar to those found in the references. ${ }^{6}$ The Se-O distances range between $1.671(4)$ and $1.713(5) \AA$, which are comparable to those reported in other metal selenites..$^{3.7}$ The $\mathrm{S} 1$ and $\mathrm{S} 2$ atoms have a four-coordinated tetrahedral geometry. coordinated by four oxygen atoms with the $\mathrm{S}-\mathrm{O}$ bond lengths between $1.446(5)$ and $1.508(5) \AA$, which is normal for a $\mathrm{SO}_{4}{ }^{2}$ moiety. The $\mathrm{Cd} 1$-centered octahedra link to each other via $\mathrm{SO}_{4}^{2}$ moieties, yielding a $\mathrm{Cdl}$ chain along $a$ axis (Figure 2). While the Cd2-centered one-face centred octahedra connect together via $\mathrm{SeO}_{5}^{2}$ groups to form a $\mathrm{Cd} 2$ chain along $a$ axis. Two $\mathrm{Cdl}$ chains interconnect through cornershare to construct a double chain, of which both sides are connected by two $\mathrm{Cd} 2$ chains via corner-shared oxygen atoms and bridging $\mathrm{SO}_{4}{ }^{2}$ moieties, yielding a quadruple 21-1-2 chain running along $a$ axis, as shown in Figure 2(a). Interestingly, in 1 , there is another quadruple $4-3-3-4$ chain, which is different from the quadruple 2-1-I-2 chain. The $\mathrm{Cd} 3$-centered decahedra connect to each other wa $\mathrm{SeO}_{\mathrm{s}^{2}}$ groups to form a $\mathrm{Cd} 3$ chain along $a$ axis. Two $\mathrm{Cd} 3$ chains interconnect to each other via edge-share to form a $\mathrm{Cd} 3$ double chain. The Cd4-centered octahedra link to each other via $\mathrm{SO}_{4}{ }^{2}$ moieties, yielding a $\mathrm{Cd} 4$ chain along $a$ axis. Fach $\mathrm{Cd} 3$ double chain is connected by two $\mathrm{Cd} 4$ chains via corner-share, edge-share and $\mathrm{SO}_{4}{ }^{2-}$ moieties, constructing a quadruple 4-3-3-4 chain running along $a$ axis [Figure 2(b)]. In a word, in the quadruple 2-1-1-2 chain, the polyhedra are interconnected via corner-share and $\mathrm{SO}_{4}{ }^{2}$ moieties, while in the quadruple 4-3-3-4 chain, the polyhedra are interconnected via corner-share, edge-share and $\mathrm{SO}_{4}{ }^{2}$ moieties. Fach quadruple 2-1-1-2 chain interconnects to four $4-3-3-4$ chains through corner-share, edge-share, $\mathrm{SeO}_{3}{ }^{2}$ and $\mathrm{SO}_{4}{ }^{2}$ moieties to build a 3-D structure, as shown in Figure 3.

A noteworthy feature of $\mathbf{1}$ is the $\mathrm{MO}_{8}$ decalhedron, which is the first example in metal selenites, although many $\mathrm{MO}_{4}{ }^{3}$ $\mathrm{MO}_{5,}{ }^{7} \mathrm{MO}_{6}{ }^{8}$ and $\mathrm{MO}_{7}{ }^{7}$ polyhedra in metal selenites have been reported. Another structural feature of 1 derives from the fact that there are three kinds of coordination geometries of cadmium (six-, seven- and eight-coordination geometries)

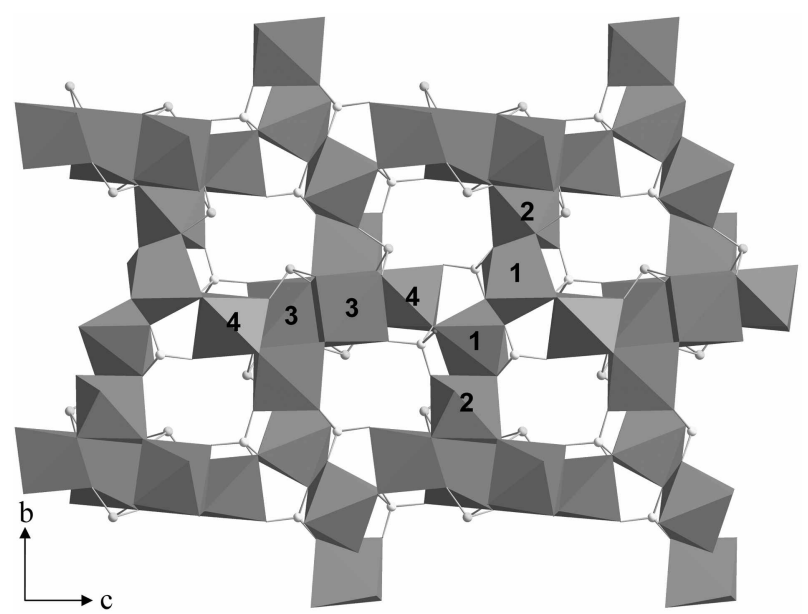

Figure 3. Polyhedral representation of the 3-D structure of 1. Yellow: S. gren: Se. Numbers are the erystallographically distinet cadnium atoms. coexist in the structure, which is not common in cadmiumcontaining compounds.

To our knowledge, only one metal selenite-sulfate, in which the metal is molybdenum, ${ }^{10}$ has been documented so far, although several inetal selenate-sulfates have been reported. " Therefore, compound 1 is the first group- 12 metal selenite-sulfates and the second example of metal selenite-sulfates.

For the structure of 1 , a Flack $x$ parameter of $-0.00(1)$ was calculated, indicating a correct absolute structure. ${ }^{12}$ Results of the bond valence calculations indicate that all the cadmium atoms are in +2 oxidation state $(\mathrm{Cd} 1: 1.939 . \mathrm{Cd} 2$ : 2.001, Cd3: 1.950, Cd4: 2.241). ${ }^{13}$ The calculated bond valences are 4.093 and 4.084 for Sel and Se2, respectively. suggesting that $\mathrm{Sel}$ and $\mathrm{Se} 2$ atoms are in +4 oxidation state. All the $S$ atoms are in +6 oxidation state, which is consistent with the bond valence calculation ( $\mathrm{S1}: 6.099, \mathrm{~S} 2: 5.948$ ).

Optical absorption spectrum of compound 1 reveals an optical gap of $1.62 \mathrm{eV}$ (Figure 4), which suggests that compound 1 may be a semiconductor and is consistent with the color of the crystals. ${ }^{\text {lt }}$ The gradual slope of the optical absorption edge is indicative of the existence of indirect transition. ${ }^{15}$ The energy band gap of $\mathbf{1}$ is comparable with those of Cdle (1.5 eV), GaAs (1.4 eV) and CulnS $2(1.55$ $\mathrm{eV}$ ), all of them are highly efficient photovoltaic materials. ${ }^{16}$

In summary, the first example of group-12 selenitesulfates, $\mathrm{Cd}_{4}\left(\mathrm{SeO}_{3}\right)_{2}\left(\mathrm{SO}_{4}\right)_{2}$ (1), has been synthesized via hydrothermal reaction. The transparent and acentric nature of 1 suggests that it may have nonlinear optical property. Future investigations on the relationship between the crystal structure and the properties in this field are in progress.

\section{Experimental Section}

Al] reactants of A.R. grade were obtained commercially and used without further purification. The UV-vis spectra were recorded at room temperature on a computer-controlled PE Lambda $900 \mathrm{UV}$-vis spectrometer equipped with an integrating sphere in the wavelength range $190-2500 \mathrm{~nm}$. $\mathrm{BaSO}_{4}$ plate was used as a reference ( $100 \%$ reflectance), on which the finely ground powder of the samples were coated.

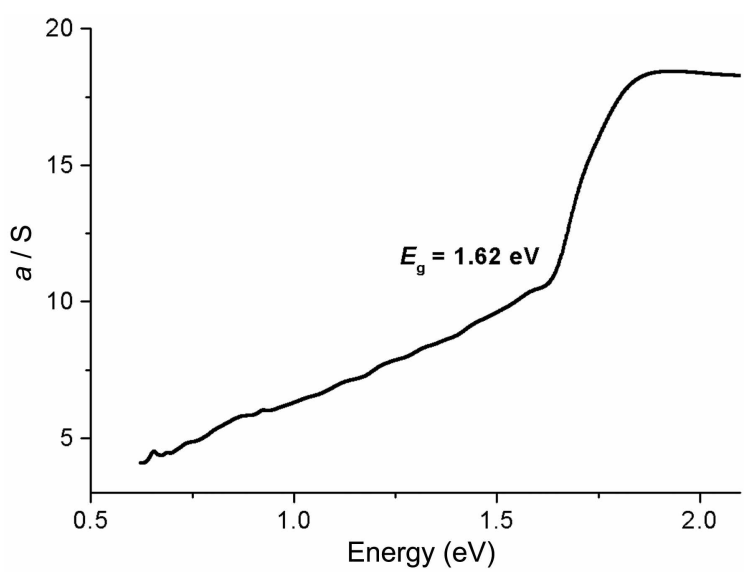

Figure 4. The solid-state diffuse reflectance spectrum of $\mathbf{1}$. 
Table 1. Summary of crystallographic data and stuncture analysis

\begin{tabular}{llll}
\hline Formula & $\mathrm{Cd}_{4} \mathrm{O}_{1+} \mathrm{S}_{2} \mathrm{Se}_{2}$ & $\Gamma^{*}\left(\AA^{3}\right)$ & $1241.5(3)$ \\
$F_{W}$ & 895.64 & $Z$ & 4 \\
Crystal system & orthorhombic & Reflections collected & 8091 \\
Space group & $P 2_{1} 2_{1} 2_{1}$ & Independent & 2190 \\
$a(A)$ & $5.3524(7)$ & $t a\left(\mathrm{~mm}^{-1}\right)$ & 13.036 \\
$b(\AA)$ & $14.595(2)$ & $T(\mathrm{~K})$ & $293(2)$ \\
$c(A)$ & $15.892(2)$ & $R 1, w R 2$ & $0.0197,0.0461$ \\
\hline
\end{tabular}

Table 2. Selected bond lengths $(\AA)$

\begin{tabular}{|c|c|c|c|}
\hline $\mathrm{Cdl}-\mathrm{O} 2$ & $2.421(5)$ & $\mathrm{Cd} 3-\mathrm{O} 9 \# 3$ & $2.508(4)$ \\
\hline Cdl-O $\# 1$ & $2.261(5)$ & $\mathrm{Cd} 3-\mathrm{O} 9 \# 5$ & $2.506(4)$ \\
\hline Cdl-OA\#2 & $2.264(4)$ & $\mathrm{Cd} 3-\mathrm{O} 10 \# 3$ & $2.395(4)$ \\
\hline Cdl-O5 & $2.528(4)$ & $\mathrm{Cd} 3-\mathrm{Oll}$ & $2.322(4)$ \\
\hline Cdl-O8\#3 & $2.302(4)$ & $\mathrm{Cd} 3-\mathrm{Oll} \# 5$ & $2.415(4)$ \\
\hline $\mathrm{Cd} 1-\mathrm{Ol} 2 \# 1$ & $2.236(4)$ & $\mathrm{Cd} 3-\mathrm{O} 13 \# 6$ & $2.431(4)$ \\
\hline $\mathrm{Cd} 2-\mathrm{O} 2$ & $2.263(4)$ & $\mathrm{Cd} 3-\mathrm{Ol} 4 \mathrm{~A} 6$ & $2.556(4)$ \\
\hline $\mathrm{Cd} 2-\mathrm{O} 7 \# 3$ & $2.44(4)$ & $\mathrm{Cd} 4-\mathrm{Ol} \# 7$ & $2.233(4)$ \\
\hline $\mathrm{Cd} 2-\mathrm{O} 9 \# 3$ & $2.236(4)$ & Cdit-O5\#8 & $2.275(4)$ \\
\hline $\mathrm{Cd} 2-\mathrm{Oll}$ & $2.572(4)$ & Cdt-O8\#9 & $2.332(4)$ \\
\hline $\mathrm{Cd} 2-\mathrm{Ol} 2$ & $2.455(5)$ & $\mathrm{Cd}+\mathrm{Ol}$ & $2.217(4)$ \\
\hline $\mathrm{Cd} 2-\mathrm{Ol} 3 \# 1$ & $2.305(4)$ & Cd4-Ol $3 \# 1$ & $2.343(4)$ \\
\hline $\mathrm{Cd} 2-\mathrm{Ol} 4$ & $2.40(4)$ & $\mathrm{Cd}+\mathrm{Ol} 4$ & $2.230(4)$ \\
\hline $\mathrm{Cd} 3-06 \# 4$ & $2.342(4)$ & & \\
\hline
\end{tabular}

Symmetry codes: $+1 \mathrm{x}-1$. y, $\mathrm{z}: 2 \mathrm{x}-1: 2 .-\mathrm{y}-3: 2,-\mathrm{z}-3:+3 \mathrm{x}-1, \mathrm{y}, \mathrm{z}: 44$

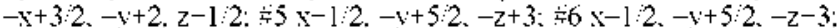
$47-\mathrm{x}-52,-\mathrm{y}-2, \mathrm{z}-1 ; 2 ; \div 8-\mathrm{x}-2, \mathrm{y}+122,-\mathrm{z}+52 ; \div 9-\mathrm{x}-1, \mathrm{y}+122,-\mathrm{z}+52$

The absorption spectra were calculated from reflection spectra by the Kubelka-Munk function: ${ }^{17} \alpha / S=(1-R)^{3 / 2 R}$. $\alpha$ is the absorption coefficient. $S$ is the scattering coefficient which is practically wavelength independent when the particle size is larger than $5 \mu \mathrm{m}$. and $R$ is the reflectance.

$\mathrm{Cd}_{4}\left(\mathrm{SeO}_{3}\right)_{2}\left(\mathrm{SO}_{4}\right)_{2}(\mathbf{1}) . \mathrm{CdBr}_{2} \cdot 4 \mathrm{H}_{2} \mathrm{O}$ (l mmol. $\left.344 \mathrm{mg}\right) . \mathrm{S}$ (2 nimol. $64 \mathrm{mg}$ ) and Se ( $2 \mathrm{mmol}, 158 \mathrm{mg}$ ) were ground into fine powders in an agate mortar and loaded into a pyrex tube. then added $0.1 \mathrm{~mL}$ water. The tube was flame-sealed under a $10^{-\hat{3}}$ Torr atmosphere and subsequently placed into a furnace. The tube was heated from room temperature to $450^{\circ} \mathrm{C}$ in $6 \mathrm{hrs}$ and kept at this temperature for 6 days. followed by cooling to $100^{\circ} \mathrm{C}$ at a rate of $6^{\circ} \mathrm{C} / \mathrm{h}$ to promote crystal growth and then power off

$\mathrm{X}$-ray diffraction data were collected on Bruker APEX-II $\mathrm{X}$-ray diffractometer with graphite monochromated Mo- $K \alpha$ radiation $(\lambda=0.71073 \AA$ ) using $\varphi$ and $w$ scan techniques. APEX2 software was used for data reduction and multi-scan absorption correction. The structure was solved by the direct methods using the Siemens SHELXTL ${ }^{\text {TMI }}$ Version 5 package of crystallographic software. The difference Fourier maps based on the atomic positions yield all atoms. The structure was refined using a full-matrix least-squares refinement on $F^{2}$. All atoms were refuned anisotropically. The sumunary of crystallographic data and structure analysis is listed in Table 1. The selected bond lengths are listed in Table 2 .

Acknowledgment. We gratefully acknowledge the funancial support of the NSF of China (50572030) and the NSF of Fujian Province (2004HZ01-3)

\section{References}

1. Wickleder. M. S. Chem. Rev: 2002. 102.2011.

2. (a) Asai, T.: Kiriyama. R. Bull. Chem. Soc. Jpu. 1973. 46. 2395 (b) Morris, R. E.: Cheetham, A. K. Chem Hater 1994, 6. 67. (c) Gopalakrishnan, J. Chem. Mater: 1995, 7, 1265. (d) El-Sayed. B A.: Emara. A. A. A.: Abd El-Hameed. F. S. M.: Shaaban1. S. M. Mater Lett. 1996. 27. 247.

3. (a) Galy. I: Meunier. G.: Andersson. S.: Anstrom. A. J. Solid State Chem. 1975. 13, 142. (b) Shiv, H. P.: Poeppelmeier, K. R. Chem. Hater. 1998. 10,2753. (c) Almond, P. M: A-Sclumitt. T. E. Inorg. Chem. 2003. 42, 5693. (d) Udavakumar. D. Rao, C. N. R. Mater Chent 2003. 13. 1635. (e) Pasha. I.: Choudhury. A.: Rao. C. N. R. Solid State Sci. 2003. 5. 257. (f) Millange. F.: Serre. C.: Cabourdin. T.: Marrot. J.: Férey. G. Solid State Sci. 2004. 6. 229

4. (a) Balraj, V.: Vidvasagar, K. Inorg. Chem. 1999. 38. 5809. (b) Johnston, M. G.; Harrison. W. T. A. Ihorg. Chem. 2001. 40.6518 (c) Goodey. J.: Broussard. J: Halasyamani. P. S. Chem. Mater. 2002. 14. 3174 . (d) Ra. H.-S.: Ok. K.-M.: Halasyamani. P. S. J. Ant Chent Soc. 2003.125 .7764$.

5. (a) Kim. Y.-T.; Kim. Y.-H.: Park. K.; Kwon, Y.-U. J. Solid State Chem. 2001, 161. 23. (b) Paul, G.: Choudhury, A.; Rao. C. N. R. d. Chem. Soc. Dalton Trans. $2002,3859$.

6. (a) Tohnston. M. G.: Harrison. W. T. A. J. Solid State Chem. 2004. 177. 4316. (b) Shent. Y.L.: Mao. J.-G.: Jiang. H.-L. J. Solid State Chent 2005. 178.2949

7. (a) Dai, Z, M.: Shi. Z; Li, G. H.; Chen, X. B.: Lu, X. Y; Xu, Y. H: Feng. S. H. J. Solid State Chem. 2003. 172. 2015. (b) Dai. Z. M: Shi. Z.: Li, G. H.: Zhang. D.: Fu. W. S: Jin, H.; Xu, Y. W.: Feng. S. H. horg. Chem. 2003. 42.7396

8. (a) Dai. Z. M.: Li. G. H.: Shi. Z.: Fu. W. S.: Dong. W. J.: Xu. J.: Feng. S. H. Solid State Sci. 2004. 6. 91. (b) Kortz. U.: Savelieft. M. G.: Ghali. F. Y. A.: Khalil. L. M.: Maalouf. S. A.: Sint1o. D. I. Angew: Chem., Int Ed. 2002. 41, 4070 .

9. (a) Mistryukov. V. E.: Milhailov, Y. N. Koord Khim. (Russ. (Coord. Chem.) 1983, 9.97. (b) Mikhailov, Y. N.: Gorbunova, Y. E.: Shishlina. O. V.: Serezhkina. L. B.: Serezhkinl. V. N. Zh. Neorg. Khint (Russ) (Russ J. Whorg. Chem.) 1999. H. 1448.

10. Robl. C.: Haake. K. J. Chem. Soc. Chent Conmm 1993. 397.

11. (a) Mestres. L.; Martinez. M. L.; Rodriguez, A. Z. Kristallog: 1987. 180. 179. (b) Slater, P. R:- Greaves, C. J. Mater: Chem. 1994. 4. 1463. (c) Slater. P. R.; Greaves, C. J. Hater: Chom 1994 t. 1469.

12. Bernardinelli. G.: Flack. H. D. Acta Chstallogr. Sect. A 1985. +1 500 .

13. (a) Brown. I. D.: Altermat. D. Acta Constallogr: B 1985. $41,244$. (b) O'Keeffe. M.: Brese. N. E. J. Am. Chem. Soc. 1991. 113. 3226 .

14. (a) Choi. K.-S.: Kanatzidis. M. G. Inorg. Chem. 2000. 39. 5655 (b) Aitken. T. A.: Chondroudis. K.: Young. V. G.: Kanatzidis. M. G. Inorg Chem. 2000. 39. 1525. (c) Chondroudis. K.: Kanatzidis. M. G. Inorg. Chem. 1998. 37, 3792. (d) Chondroudis. K.: Hanko. J. A.: Kanatzidis. M. G. Inorg. Chem. 1997. 36, 2623.

15. Huang. F. Q: Mitchell. K.: Ibers, J. A. Inorg. Chem 2001, to, 5123.

16. (a) Zweibel. K.: Mitchell. R. In CulnSe2 and CdTe: Scale-lp for Mamufactuing. SERI Publication. prepared for US DOE under Contract No. DE-ACO2-83CH10093. 1989. (b) Champness, C. H. Phosphorous Sulfor Relat. Elem. 1988. 38, 385. (c) Dube. R. H. Photovoltaic 1 Aaterials: Imperial Colleage Press: 1998; p 184. (d) Dürichent. P.: Bensch. W. Eum J. Soldd State horg. Chem. 1997. 34. 1187. (e) Tillinski. R.: Rumnf. C.: Näther. C.: Dürichent. P.: Jess. I.: Schunk. S. A.: Bensch. W. Z. Anong Allg. Chem. 1998. 624.1285

17. (a) Wendlandt. W. W: Hecht, H. G. Reflectance Spectoscopy; Interscience Publishers: New York. 1966. (b) Kortüm. G. Reflectance Spectroscopl: Springer Verlag: New York. 1969 